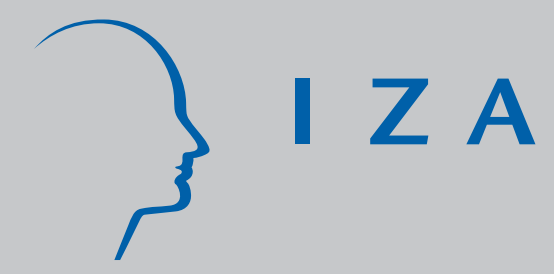

IZADP No. 4057

The Impact of Education on the Subjective Discount Rate in Ugandan Villages

Michal Bauer

Julie Chytilová

March 2009 


\title{
The Impact of Education on the Subjective Discount Rate in Ugandan Villages
}

\author{
Michal Bauer \\ Charles University Prague \\ and IZA \\ Julie Chytilová \\ Charles University Prague
}
Discussion Paper No. 4057
March 2009

\author{
IZA \\ P.O. Box 7240 \\ 53072 Bonn \\ Germany \\ Phone: +49-228-3894-0 \\ Fax: +49-228-3894-180 \\ E-mail: iza@iza.org
}

\begin{abstract}
Any opinions expressed here are those of the author(s) and not those of IZA. Research published in this series may include views on policy, but the institute itself takes no institutional policy positions.

The Institute for the Study of Labor (IZA) in Bonn is a local and virtual international research center and a place of communication between science, politics and business. IZA is an independent nonprofit organization supported by Deutsche Post Foundation. The center is associated with the University of Bonn and offers a stimulating research environment through its international network, workshops and conferences, data service, project support, research visits and doctoral program. IZA engages in (i) original and internationally competitive research in all fields of labor economics, (ii) development of policy concepts, and (iii) dissemination of research results and concepts to the interested public.
\end{abstract}

IZA Discussion Papers often represent preliminary work and are circulated to encourage discussion. Citation of such a paper should account for its provisional character. A revised version may be available directly from the author. 


\section{ABSTRACT \\ The Impact of Education on the Subjective Discount Rate in Ugandan Villages}

Heterogeneity in time discounting may reinforce the existing barriers to save and invest faced by rural populations in developing countries. We elicit a subjective discount rate for a varied sample of Ugandan villagers. In accordance with other studies, we have found the discount rate to decrease with education. We examine this correlation further by testing the causal effect of education and exploit two different sources of its variation: school frequency across villages and the number of the respondents' school-going years that overlap with the era of the dictator Idi Amin's rule. For men, we find that education has a significant impact on their discount rate, similar in magnitude for both types of instruments and robust to observable characteristics. This finding highlights the importance of education in development.

JEL Classification: C93, D91, O12

Keywords: $\quad$ time discounting, patience, education, economic development, Uganda

Corresponding author:

Michal Bauer

Institute of Economic Studies

Charles University in Prague

Opletalova 26

Prague 1, 11000

Czech Republic

E-mail: bauerm@fsv.cuni.cz

\footnotetext{
* We are very grateful to R. Filer, I. Gang, A. Ortmann, M. Skořepa, and anonymous referees for many helpful comments. We have benefited from discussions with O. Bandiera, T. Cahlík, J. Hlaváček, O. Knot, M. Mejstřík, A. Morjaria, D. Munich, P. Streblov, F. Žikeš and participants of several conferences and seminars. We would also like to thank the Uganda Czech Development Trust (UCDT) for the collaboration on the field research and STICERD for support at later stages of the research. We gratefully acknowledge the financial support from MSM0021620841. All errors are ours.
} 


\section{Introduction}

The question why there is not more indigenous saving and investment in less developed countries lies at the core of many debates among development economists. Goldstein and Udry (1999) estimated rate of return to the production of pineapple in Ghana to be in excess of $1,200 \%$. However, very few people decided to grow pineapple even though doing so requires only a moderate initial investment which could be covered by a loan collateralized by the farmers' land. Likewise, in Kenya, Duflo, Kremer and Robinson (2006) found that less than $20 \%$ of maize farmers in the area in which they conducted field trials on the profitability of fertilizer report that they had used fertilizer, despite an estimated rate of return in excess of $150 \%$. The limited responsiveness to high marginal product in poor countries is usually attributed to market failures of various kinds (for a survey see Banerjee and Duflo 2004). Recently, growing attention has been directed towards behavioral issues and psychological barriers that limit saving and investment decisions not by affecting the constraints, but by changing the decision-making process (Duflo 2006; Mullainathan 2005).

An interaction between time discounting and individual characteristics such as education or wealth could also partially explain these observations. However, as noted by Anderson et al. (2004), we have surprisingly little empirical evidence regarding the process through which discount rates are formed, especially in countries with less developed economic institutions. In this paper we study the sample of Ugandan villagers. Most importantly, the study provides empirical evidence on the causal impact of education on the subjective discount rate.

There are good reasons as to why education may lower discount rate. In their model of the endogenous discount rate, Becker and Mulligan (1997) argue that education can be understood as an investment in patience. Education can help one to form a mental picture of one’s future pleasures and difficulties in life and enhances the process of anticipation. In 
addition, through repeated practice at problem-solving, education helps one to learn the art of scenario simulation. In this way, education can be understood as a tool that helps people to perceive future pleasures as less remote. As Böhm-Bawerk (1891, p.244) writes: “The present always gets its rights. It forces itself upon us through our senses. To cry for food when hungry occurs even to a baby. But future we must anticipate and picture... We must be able to form a mental picture of what will be the state of our wants, needs, feelings, at any particular point of time.”

Psychological studies demonstrate that humans are born impatient (Mischel, Shoda and Rodriguez 1989; Metcalfe and Mischel 1999). Learning to be future-oriented and to choose actions with a postponed reward is an essential part of our upbringing and educational process. Without such learning, people would live solely within the present without much will to resist current temptations and would simply omit future pleasures from their decisionmaking process (Doepke and Zilibotti 2006; Shonkoff and Phillips 2000).

Studies that extend their samples beyond the usual pool of university students often find a correlation between education level and discount rate. In the major study that elicits discount rate in a developed country Harrison, Lau and Williams (2002) showed on a representative sample of Danish households that highly educated adults have subjective discount rates as low as two thirds of those less educated. ${ }^{1}$ In less developed countries, the difference is likely to be even more profound, as there may be additional pathways through which education can increase patience. Kirby et al. (2002) studied discount rate in two remote villages in the Bolivian rain forest. They found high average discount rate and that a large

\footnotetext{
${ }^{1}$ Another important study from a developed country is Dohmen et al (2007) who find negative correlation between cognitive ability and discount rate in Germany. Their result is broadly consistent with hypothesized effect education, because education is likely to improve cognitive ability. For a comprehensive survey of studies that elicit subjective discount rate in developed countries see Frederick, Loewenstein and O’Donoghue (2002). Cardenas and Carpenter (2005) survey studies from lower-income countries.
} 
proportion of its variance can be explained by years of schooling, parental education and measures of qualitative education achievements in terms of mathematics and language proficiency. Similar results were obtained in rural areas in India by Bauer and Chytilová (2008). In their study of subjective discount rates in Vietnam, Anderson et al. (2004) emphasize the importance of education although they do not specifically measure it. Pender (1996) and Tanaka et al. (2006) find a relationship between patience and income in India and Vietnam, respectively.

This paper should complement the earlier evidence in two ways. First, to our knowledge, the direction of causality between education and discount rate has not been addressed by any of the previous studies that have elicited discount rates. To estimate the impact of education on the discount rate, we use information on varying school frequency in different villages and the number of school-age years that overlap with the era of Idi Amin as reasonably exogenous sources of variation in education. Second, our sample was drawn from members of a rural society less influenced by modern market structures (e.g., credit markets) than undergraduates from affluent societies who are the usual subjects in this type of study. The environment is also very different compared to a few earlier studies from less developed countries.

The paper proceeds as follows: In Section 2 we describe the survey design and discuss issues related to measuring discount rate. In Section 3 we show the relationship between the discount rate and individual characteristics and demonstrate the causal effect of education on discount rate. Section 4 concludes.

\section{Survey Design}

2.1 Measuring time discounting 
Numerous methods have been used to measure individual discounting (Frederick et al. 2002). Before analyzing our results, we discuss the advantages and disadvantages of this type of study.

We used choice task method to elicit discount rate (Frederick et al. 2002). Individuals were asked to express their preference between receiving a smaller reward immediately and receiving a larger reward with some delay. Starting with the question, "Would you prefer to

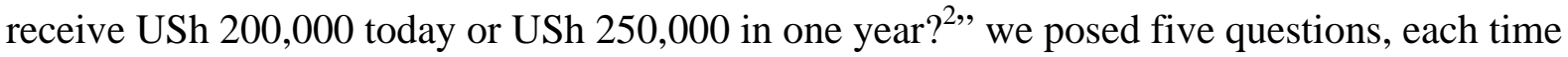
increasing the amount offered in the future. As we increased the future amount, we expected more individuals to select the future option. The point at which a respondent switches from the current amount to the future amount provides the range for his/her discount rate and the midpoint of the range is our best estimate of the person's discount rate. The amount in question was set relatively high so as to be relevant for important savings or investment choices. In particular, we had in mind the situation of many farmers in southern Uganda who were growing vanilla in 2004 and due to the boom in the international vanilla market had substantially higher income than they expected. ${ }^{3}$

Proper understanding of the time-discounting questions is particularly important in an environment with low average education levels. Two rounds of pre-testing with ten respondents were done to limit systematic misunderstanding, and the questionnaires were adjusted based on follow-up discussions. ${ }^{4}$ The respondents' ability to understand the

\footnotetext{
${ }^{2}$ In November 2005, the exchange rate was 1,830 USh to USD.

${ }^{3}$ As of 2005 Uganda numbered among the ten largest producers of vanilla, with Madagascar producing almost $60 \%$ of the overall world vanilla production. At the end of 1990s price of vanilla was around USD 40 per kg. The typhoon and political instability in Madagascar drove vanilla prices to USD 500 per kg at the beginning of 2004 (Uganda Export Promotion Board 2006).

4 The major decision resulting from the pretest was not to use the matching-task method for eliciting discount rate (used in e.g. Anderson et al. 2004), when respondents are asked to stipulate a monetary amount that equates
} 
discount-rate questions based on binary choices was later checked by observing how many respondents from the whole sample switched back to the current income option after preferring future income in the previous binary choice. In the sample, less than $3 \%$ of respondents gave inconsistent answers. In addition, we test whether less-educated individuals are more likely to answer inconsistently and find that inconsistent responses are uncorrelated with education, and also with any other observed characteristics. As mentioned earlier, the inconsistent responses were not included into the analysis.

An important design choice is whether to use real or hypothetical rewards. In studies involving hypothetical rewards, respondents can be presented with a wider range of reward options, including relatively large gains, which are generally infeasible in studies involving real outcomes. As mentioned above, our aim was to approximate a financial decision of similar magnitude as unexpected income gains during the period of high vanilla prices in 2004. On the other hand, with hypothetical rewards there is a legitimate concern that respondents will have little incentive to work hard or thoughtfully on their responses (Harrison et al. 2005), in which case, our measure would yield a noisy estimate of discounting. Several experimenters have directly compared discount rates based on real and hypothetical rewards. While Kirby and Marakovic (1996) and Coller and Williams (1999) found lower discount rates for hypothetical choices than for real choices, Johnson and Bickel (2002), Madden et al. (2003) and Hamoudi and Thomas (2006) did not observe this difference in their experiments. There has also been considerable debate outside of the context of inter-temporal choice on this issue. The general conclusion from this debate is that

two intertemporal options. We found that the respondents participating in the pretest had difficulties understanding this task properly. Therefore, we opted for choice-task method, which is simpler although it generates less precise estimates of discount rate. On more detailed comparison of relative advantages between these two methods see Frederick et al. (2002). 
the two methods typically yield qualitatively similar results, although financial incentives often decrease the variance of responses (Camerer and Hogarth 1999).

In traditional communities the person or institution that organizes an experiment is a particularly important parameter in terms of how local people approach the assigned tasks. The high social status of, and respect for, our instructors (social workers) within the village community should help to mitigate the possible problem of missing monetary incentives. ${ }^{5}$

A related question in terms of the validity of elicited discount rate is its relevance to economic decisions. For example, Binswanger (1980) experimentally measured aversion to risk in rural India and found that individuals with a higher degree of risk aversion choose more conservative agricultural strategies. In our sample we found that more patient respondents are more likely to use a mosquito net and assign higher importance to child schooling in their fertility decisions. The correlation with the discount rate is -0.089 (p-value $=0.010)$ and $-0.086(\mathrm{p}$-value $=0.012)$, respectively.

There are a few reliability issues related specifically to the choice task method for eliciting discount rate. Binary choices do not reveal a single indifference point that would allow a single discount rate to be inferred. Instead, they provide a range of inferred discount rate. The amounts offered in the questions may themselves communicate to respondents how much they should be discounting, resulting in a framing effect. The total range between the lowest and highest discount rate may not be sufficient to cover the preferences of some of the respondents. Although we increased the range upwards after pre-testing, the upper bound was still not high enough for many respondents, who chose the current option even in the last pair

\footnotetext{
${ }^{5}$ According to the feedback from the instructors the survey questions were a favourite topic for local people to discuss during their free time in the evenings after the survey. This deliberate expression of interest also suggests that the survey was a special event in the lives of local people and that respondents were serious in their responses.
} 
in which the future option was highest. In the statistical analysis we employed $650 \%$ as a censoring value for these responses.

Lastly, researchers have found that the discount rate is not a constant and it may differ due to the effect of delay, size and sign of the amount in question (Frederick et al. 2002). The smaller the amount, the higher the discount rate is. Discount rates for losses seem to be smaller than discount rates for gains. Discount rates seem to be higher for short delays - e.g. three days - than for long delays - e.g. one year. Respondents in our study were deciding about a relatively high gain with alternative amount to be given one year later.

These caveats are particularly relevant for comparison of the absolute values of discount rates across different studies. For the purposes of this study, it is important to note that we are primarily interested in differences of discount rate across socioeconomic characteristics within our sample and not in particular absolute values. The respondents are facing the same protocol and it is plausible to assume that any biases in terms of effort and understanding are not systematic across different groups. In other words, we assume they do not depend on the examined explanatory variable and we therefore believe that the significance of observed relationships should be unaffected by the issues discussed above.

\subsection{Sample}

This study is based on data from a questionnaire survey that was conducted in ten village areas in the Mukono district, which is located in the southern part of Uganda. The district is primarily rural with an economy based on small-scale subsistence farming and local market trade. People usually grow maize, vegetables, plantain bananas, cassava, vanilla and coffee. The vast majority of households in this region are very poor by any standards, with an average per capita income of less than USD 300 a year and life expectancy at birth reaching only 46 years, largely due to the effects of malaria and HIV/AIDS (World Development 
Indicators 2005). 85\% of Ugandan inhabitants live in rural areas with similar characteristics (Uganda Bureau of Statistics (UBOS) 2002). Uganda is a low-inflation country and its inflation levels do not differ significantly from those in developed economies. ${ }^{6}$

Data were collected in November 2005 in cooperation with UCDT, a Czech-Ugandan NGO in the ten village areas. Because there are no lists of area residents available to allow us to employ the random selection method, we used a combination of the random walk method and quota sampling in our sampling procedure. We stipulated four groups in terms of age and education so that the proportion of participants within each of these groups corresponded to the overall rural statistics (UBOS 2002). The target population was restricted to literate individuals above 15 years. Only a few selected individuals did not agree to participate.

A total of 910 respondents participated. The respondents were not time-constrained when filling out the questionnaires. Most of them did not have previous experience with filling out such questionnaires and they approached the task very responsibly. On average they spent one and a half hours answering the questions. In all, 54 questionnaires were not filled out completely ${ }^{7}$. The incomplete questionnaires are excluded from the analysis and our sample size reduced from 910 to 856 respondents.

We collected information on individual characteristics, specifically regarding age, education level, marital status, clan linkage and profession. Table 1 shows the summary statistics of the sample. The level of education was measured by the number of school classes completed by the respondent. The average educational attainment in our sample is higher than that of Uganda as a whole, where only $38 \%$ of children complete primary school (UBOS 2002), as compared to 70\% in our sample. The questionnaires were bilingual - in English and

\footnotetext{
${ }^{6}$ The average inflation rate for the period 2000-2004 was 4.3 percent (World Development Indicators 2005).

${ }^{7} 28$ respondents either did not answer consistently the question on discount rate or they did not answer this question at all. Another 26 answered the question on discount rate but did not give information on one of the individual characteristics (usually age, as not knowing one's precise date of birth is quite common in the area).
} 
Luganda - to allow us to approach less educated people who speak only Luganda ${ }^{8}$. Illiterate individuals could not participate. The Ugandan illiteracy rate among people aged over 15 years is 31\% (World Development Indicators 2005). Illiteracy explains why our respondents are more educated and younger than the Ugandan averages.

Income is approximated by individual profession since, as we found during a pretest, respondents were generally uncomfortable with revealing their income. The sample is divided into four groups: self-employed farmers, self-employed non-farmers (shopkeepers and drivers), employees (mostly teachers and employees of NGOs) and others (students and those who did not fit any of the previous categories). Strength of clan is a binary variable that indicates self-reported embeddedness within family structures and is based on a survey question about clan influence on fertility decision-making.

The respondents were also asked about mosquito net usage and self-reported importance of child schooling. The purpose of these two variables is to cross-check the relevance of the elicited hypothetical discount rate to actual behavior in delayed-reward situations.

The respondents indicated their village of residence. This information, jointly with age, allows us to approximate access to educational facilities during the individual's school years. We match this information with data from UBOS and the Ugandan Ministry of Education to calculate the number of primary and secondary schools per thousand inhabitants in the given village area for different cohorts.

\section{Correlates of discount rate}

\footnotetext{
${ }^{8}$ The official language in Uganda is English. The different local languages reflect the tribal divisions within Uganda. Luganda is the language of the Baganda people - the largest tribe in Uganda.
} 
Although the discount rate is perhaps biologically determined to some degree, it is reasonable to regard it as not immutable. We will now explore how individual characteristics are able to predict the discount rate. In Table 2 we compare the mean discount rate for different sub-groups without controlling for other observable characteristics.

First, we find that more educated individuals have a lower discount rate. For example, men and women who studied at a secondary school have a significantly lower discount rate than those who did not. As described earlier, this correlation has been found in various studies in different contexts. The result is consistent with the proposition that education makes individuals more patient by enhancing their ability to plan and/or by increasing their permanent income (Becker and Mulligan 1997). Alternatively, more patient individuals might be more willing to delay gratification and invest in their human capital or there could be an omitted variable, such as intelligence, which would account for both the discount rate and the differences in education level. In section 4 we will address the issue of causation in detail and examine the impact of education on discount rate.

We find that self-employed farmers and non-farm workers (drivers, shopkeepers) are on average more impatient than employed individuals (teachers, employees of public bodies or NGOs) and students (a large part of the group marked as “other” in Table 2), although employed women have similar level of impatience as farmers. Although individual profession is likely to be an imprecise proxy of income, these results are broadly consistent with the hypothesis that individuals facing less income pressures discount less.

Note that similar concerns about causation discussed with regard to education are relevant to income as well. Becker and Mulligan (1997), for example, argue that wealth (and possibly income) should decrease discount rate because richer people can afford to delay consumption and invest more. Alternatively, a low income may be a result of a high discount rate and the selection of occupation with flat income profile that does not require learning and 
training (Lawrence 1991, Doepke and Zilibotti 2005). Pender (1996) and Tanaka et al. (2006) found a negative relation between income and the discount rate in India and Vietnam, respectively. Kirby et al. (2002) observed correlation with wealth, but not with income. Anderson et al. (2004) do not find correlation between these two variables, but they point out that failure to identify it may be due to the difficulty of measuring income among the poor in the field.

Older individuals in our sample discount future income more heavily than their younger counterparts. This relationship accords with the traditional economic argument based on the permanent income hypothesis, in which people are assumed to reflect their current life expectancy in their inter-temporal decisions. The shorter the expected time to death, the higher the discount rate. On average we do indeed observe this pattern; age appears to be a significant predictor of discount rate and has a positive slope.

Numerous studies from low-income countries have reported that a higher share of income in the hands of women leads to less household expenditure on current consumption (e.g., Thomas 1990). There is new experimental evidence from Mexico and India showing that women have a lower discount rate than men (Hamoudi and Thomas 2006, Bauer and Chytilová 2008). As in Kirby et al. (2002 ) and Anderson et al. (2004), we have found no evidence for this pattern.

Social arrangements within a family or groups of families (clans) may also affect discount rate. Based on his observations of village institutions in Africa, Platteau (2000) argues that reciprocal claims to financial assistance among clan members may encourage individuals to spend money faster and lower their incentives to save. A similar argument is made in the context of intra-household relations, in which women facing spousal pressure are less likely to save (Anderson and Baland 2002). We have not found any significant difference in the discount rate between married and single respondents. Respondents who report strong 
clan linkage have a higher discount rate, in accordance with the findings of Platteau (2000). As shown below, this correlation has a rather low level of significance after controlling for other variables, education in particular.

We have identified a close association between education and discount rate. In the bivariate analysis in Table 2 we allowed educated individuals to "carry with them" other characteristics which they typically have, such as income or age, and which may also affect discount rate. To probe this relationship further, in Table 3 we run a series of OLS regressions. The dependent variable is the discount rate. Observations are clustered at the village level if not explicitly specified otherwise.

In Table 3, columns 1-3 we control only for cohort and life-cycle effects by including a set of twelve dummies into the regression, one dummy for each 5-year cohort starting from 1941-45. We find that more educated individuals have a lower discount rate at $1 \%$ level. Adding controls for individual profession and family ties leaves the education coefficient and standard errors almost intact (columns 4-6). In columns 7-9 we also control for potential direct effects of village-area characteristics and include a set of village dummies into the regression, instead of clustering. The main result holds, although the coefficient for men is slightly lower.

Potentially, the results could be affected by our decision to calculate the discount rate values as the arithmetic means of the six inferred ranges. As a robustness check, we have repeated the same analysis as in Table 3 and applied an ordered probit regression instead of OLS. The results are qualitatively similar: a higher level of education predicts a lower discount rate (Appendix, Table A1).

This correlation does not help us determine the direction of the causal relationship between these two factors. To our knowledge, as yet there has been no empirical study of discount rate that has tested causal direction in the observed correlation between education 
and discount rate. The next section estimates the impact of education on discount rate using the instrumental variable technique.

\section{The impact of education on discount rate}

A solution to the problem of causal inference requires an exogenous source of variation in education (Card 1999). Long distances to school and a lack of school capacities are widely regarded as major obstacles to higher school attendance in low-income countries, especially in sub-Saharan Africa (World Bank 2002). For example, Duflo (2001) and Duflo and Breierova (2004) have convincingly demonstrated a simultaneous change in education and other variables of interest (e.g., income, fertility or child mortality) resulting from a large scale school construction program in Indonesia.

In this paper we use two different sources of variation in education: different access to schools in different villages and the effect of instability during the Idi Amin era on respective school-age cohorts. Hence, the first instrument exploits primarily the variation by region and the second instrument is based on variation over time. We show that both types of instruments deliver very similar estimates of the effect of education on discount rate for men.

\subsection{Identification strategy}

Number of primary and secondary schools

Our first type of instrumental variable is based on the observation that individuals belonging to village areas with better access to schools are more educated. We match our individual survey data with village-area-level data collected by the Ugandan Ministry of Education and Sports and UBOS. We then construct two variables to approximate access to 
schools: the number of primary schools and the number of secondary schools in a village area per one thousand inhabitants.

These instrumental variables are constructed as follows. We start with the information about the number of primary and secondary schools for each village area and the date on which they were established. ${ }^{9}$ We calculate the average number of schools for each five-year period, starting with 1941-1945 and ending with 2001-2005. Due to the rapid population growth in Uganda during 1941-2005 and potential difference in the size of village areas, ${ }^{10}$ it is more accurate to measure school access in terms of the number of schools per capita rather then the total number of schools. The number of schools is divided by the population size of the village area. Cohort specific population size of the village area is obtained by adjusting the number of inhabitants in 2002 (UBOS) for average population growth in Uganda (World Development Indicators 2006). ${ }^{11}$ Finally, each respondent is assigned the number of primary schools in the village area when she was at the age to start primary school (7 years) and the availability of secondary schools when she was at the age to start secondary school (15 years).

Table 4 shows the average number of schools per thousand people during the period 1941-2005. We can observe substantial variation in secondary school access across village

\footnotetext{
${ }^{9}$ Ideally, one would like to have panel data measuring the number of schools in village areas over time. According to our inquiries with the Ugandan Ministry of Education, these data do not exist, which is not surprising given the periods of instability in Ugandan history. As a consequence, there may be a measurement error in our constructs of school availability due to missing information about schools that were abolished before 2005 .

${ }^{10}$ According to the detailed maps which we have received from UBOS, the village areas we study are not very different from each other in terms of geographical size.

${ }^{11}$ Historical statistics about population size in each village area are not available, with the exception of the year 2002. We need to assume that the population growth was the same in all village areas.
} 
areas, but less so for primary schools. There is only a relatively small differential variation over time across villages. This prevents us from including village fixed effects to the regression analysis as these would capture the effect of varying school availability as we discuss below.

Table 5 illustrates the simple logic of our identification strategy. This table shows the means of education and the discount rate for individuals with above- and below-median access to primary and secondary education facilities (the middle and left sections of the panel, respectively). Although the results are imprecise due to the fact that only a small part of the information is used, we can observe simultaneous change in education and discount rate. Men who live in villages with better access to secondary schools have both higher education and a lower discount rate. The pattern holds with greater uncertainty also for primary schools.

Note that this identification strategy is less suitable for women than it is for men. In southern Uganda, it is common practice for a wife to move to her husband's village following their wedding (Kaduuli 2006). The instrumental variables are based on access to schools in the village area in which the respondents lived at the time of the survey, not where they lived during their schooling age. The marriage-induced migration is likely to introduce a substantial measurement error into our estimates of the effects of schools on education for women, unless there is a strong matching of couples based on achieved education level. In further analysis we will compute the estimates for men and women separately. Indeed, the (non-)results for women showed below are consistent with the notion of substantial migration.

A major threat to this identification strategy is the possibility that there are villagelevel unobservable characteristics that are correlated with the number of schools and directly affect discount rate (e.g., demand for education, access to health care). Ideally, we would like 
to include village fixed effects into our regressions to address this issue. However, our instruments are largely based on the variation in schools across villages. To examine further, we use variable that is based on variation over time as the second type of instrument and show that the results are robust to village fixed effects (similarly as the OLS estimates in Table 3).

Disorder during the era of Idi Amin

Parents are typically less motivated to send their children to school during periods of disorder. Our second type of instrument exploits the variation in education associated with the period during which the dictator Idi Amin was in power in Uganda (1971-1979). During that time, the country suffered enormous economic decline and it was inevitable that the education system would deteriorate as well (Furley 1988). Government expenditures per head fell to less than a quarter of pre-Amin levels and education expenditures further diminished as an increasing share of resources was diverted for military purposes (Stewart et al. 1997, Collier and Reinikka 2001). Amin, himself illiterate, and his regime is known for being highly suspicious of the loyalty of educated people, many of whom where targeted by the army or exiled (Furley 1988). When Amin declared an “economic war” in 1972 and expelled the Asian community out of the country, an exodus of European expatriate teachers followed, leaving enormous gaps in the teaching staff. The breakdown of contract enforcement mechanisms led to a high incidence of teachers’ absenteeism (Collier and Reinikka 2001). The quality of education declined sharply as a result. ${ }^{12}$ Appleton et al. (1996) use UNESCO estimates and report decreases in primary school enrollment between 1965 and 1975.

\footnotetext{
${ }^{12}$ There is only anecdotal evidence of the impacts on education infrastructure. Heyneman (1983) reports the effects on six schools in south Uganda (Mpigi district - close to Mukono district). In 1971 there was on average
} 
To approximate the extent to which individual education is affected by this period of instability, we simply calculate the number of years of the respondent's primary schooling age (7-14 years of age) that overlap with the period 1971-1979. The value of our instrument is the highest (8) for people born in 1964 or in 1965 who passed their entire primary schooling age during Amin's era. The value of the instrument decreases by one with each year that the individual birth year departs from 1964-1965 in either direction. It reaches zero for those born before 1957 or after 1972.

Since the instrument is based on the variation over time and our data are crosssectional, we discuss how our estimates may be affected by direct effects of age on discount rate, independently of education. In the OLS regression we have simply included a dummy for each five-year cohort to control for these effects. In 2SLS regression the effect of instability could be captured partially by the instrument and partially by the five-year cohort dummies. For this reason, we create only one dummy variable for all cohorts inside and next to the period of Amin and we keep controlling for the same five-year cohort dummies for all other cohorts. As a consequence, our instrument is the only variable which varies over time for the cohorts born between 1957-1972. Note that by its construction, our instrument can capture only u-shaped relationship with respect to time. Therefore, our estimates would be biased by direct effect of age on discount rate only in a situation, when there would be an inverted u-shaped relationship between age and discount rate, independently of education, for cohorts whose education is likely to be affected by Amin's era. We believe this is unlikely.

A potential threat to this identification strategy is that the exposure to political instability during primary-schooling age might have potentially affected time discounting via a channel other than schooling that persists over time (e.g., psychological trauma, negative

one chair for every 1.2 pupils; in 1981 there was one chair for every 8.8 pupils. Four out of the six schools did not have a single textbook in 1981, whereas these four schools had on average 84 textbooks in 1971. 
effect on health due to undernourishment during youth). Note that this type of threat is orthogonal to the concerns discussed with respect to the set of instruments based on variation in access to schools.

We expect that the higher the exposure to Amin's era, the lower the education level. In Figure 1 we show that before Amin the education of men had increasing trend, but the education of cohorts that were of primary-school age during Amin's era departs from this trend. Overall, as the exposure of respondents’ schooling age to the Amin's era increases, their level of education decreases. Those who were born in 1964-65 and therefore passed their entire primary school years during Amin's era seem to be the most affected.

For women, the education level did not decrease during the era of Amin’s rule, which suggests that the years of exposure is not a valid instrument for them. Finding reasons for this differential pattern is rather a speculative exercise; most likely it is due to the fact that cultural barriers against educating women have been gradually diminishing or that boys more than girls are needed for other activities than schooling during the periods of disorder. Similar pattern is found by other studies as well. Chesterfield et al. (2001) study the negative effect of crises on education in six countries for which the data are available (Burundi, DR Congo, Mozambique, Sudan, Nicaragua and Turkey). They find greater negative change in school enrollment for boys than for girls in all the African countries. Akresh and de Walque (2008) find the same pattern in the context of Rwandan genocide.

\subsection{Results}

Table 6 presents the main set of results for the first set of instrumental variables based on variation in access to secondary and primary schools. The lower panel shows the results of the first stage regression, where the dependent variable is years of schooling. The upper panel 
reports the second stage with the discount rate as the dependent variable. In columns 1-4 the excluded instrumental variable is the number of secondary schools. We start with controlling for cohort effects only. For men, we observe that living in villages with a higher number of secondary schools leads to a higher individual level of education; this relationship is significant at $1 \%$ level. The underidentification and weak identification tests do not reject the relevance of the instrument, either. Further, the 2SLS estimates demonstrate a significant negative effect of education on discount rate. The estimated effect using 2SLS is above the corresponding OLS estimate (Table 3, column 2). For women, we observe a negative coefficient of education, though not statistically significant.

The evidence for the causal effect of education on men's discount rate is robust to alternative specifications. In columns 3-4 of Table 6 we add (potentially endogenous) variables that may also affect discount rate, such as income related to a particular profession, marital status and individual ties to the clan. The corresponding 2SLS estimate of the effect of education is larger than the one estimated without these controls, although it is not distinguishable statistically. In columns 5-8, primary schools -- instead of secondary schools - are used as the excluded instrument for education. For men, we find similar results as those with secondary schools, but with greater uncertainty. For women, we observe that primary schools have no explanatory power for their education, which is not surprising given the above-mentioned marriage migration. Using both primary and secondary schools as instruments (columns 9-12) delivers very similar estimates of the effect of education as those found in columns 1 and 3, both in terms of the size of the effect and its significance level.

Table 7 shows the main results when the exposure to Amin's era is used as the excluded instrumental variable. In columns 1-4 we cluster the standard errors at the village level. Exposure to Amin's era lowers the education of men, whereas it does not affect women's education. In the second stage, we find that a higher level of education reduces 
men's discount rate. In contrast to the previous identification strategy, this instrumental variable allows to control directly for village fixed effects (columns 5-8). The results do not change substantively. Interestingly, the magnitude of all these estimates is very similar to the magnitude of those we obtained when using the measures of school access as instruments (Table 6).

In Table 8 we combine both types of instrumental variables. In the first stage both types of instruments strongly predict the level of education in the expected directions for men. In the second stage education reduces men's discount rate. The magnitude of the effect is similar to previous estimates reported in Tables 6 and 7, the precision is however higher (the results are significant at $1 \%$ level).

For women, the estimates go in the same direction as for men both in the first and second stage, but they are much less statistically significant. In general, our analysis for women is inconclusive. On one hand the correlation between education and the discount rate in the OLS regressions is significant at $1 \%$ level and of similar magnitude as for men. However, we do not have any suitable instrument to assess the issue of causality for women.

\section{Conclusions}

The paper aims to contribute to the rich literature that studies the causes of the low levels of saving and investment in rural parts of low-income countries. The paper focuses on the formation of time discounting as a possible explanation of this important issue and it demonstrates a causal effect of education on subjective discount rate in ten village areas in southern Uganda.

First, we study various socioeconomic characteristics that were suggested in earlier literature as possible determinants of time preference. The discount rate emerged significantly correlated with completed years of schooling: more educated respondents are more patient. 
We also found several other intuitive relationships: the respondents with a lower discount rate are more likely to make choices with delayed rewards, such as using a mosquito net or assigning higher importance to schooling of their offspring.

To our knowledge, comparable studies that elicit discount rate have not attempted to depart from the observed correlation between education and discount rate by testing the impact of education on discount rate. In order to do so, we exploit two independent exogenous sources of variation in schooling: across villages and over time. The first set of instrumental variables is based on differential access to primary and secondary schools in different villages. The second type is based on the number of individual school-age years that overlap with the rule of Idi Amin (1971-79) -- a period of overall instability characterized by a drastic decline in quality of education. For men, both instrumental variables strongly predict individual education in the expected direction. The 2SLS estimates demonstrate a significant negative effect of education on men's discount rate. Both types of instrumental variables deliver estimates of similar magnitude. The results are robust to the inclusion of a set of dummies for cohort effects, individual characteristics such as profession, family status, and, in the case of the latter instrument, for village fixed effects.

This evidence is consistent with several specific channels through which education may affect discounting. First, schooling may promote the creation of cognitive skills and the ability to simulate and plan for the future (McClure et al. 2004, Becker and Mulligan 1997). Second, education may play an important role in developing control mechanisms to manage the temptations of present consumption. This understanding resonates with the increasingly loud calls among development economists for the exploration of not only the structural constraints that poverty imposes on the decision-making of the poor but for taking seriously also the internal barriers to saving and investing in the absence of suitable institutions (Duflo 2006, Armedáriz de Aghion and Morduch 2005). A recent study from rural India (Bauer et al. 
2008), however, finds that education correlates with the level of discounting, but not with present-biased (or hyperbolic) discounting. Third, education may enhance health prevention and reduce mortality risk, which might make individuals more willing to delay their spending. Another explanation is that more educated individuals are less likely to be income constrained and face lower pressures to spend money sooner. Although the results are robust to controlling for individual profession, it might be an imperfect proxy for income and education may capture the effect of income instead.

The capacity of education to reduce time discounting further emphasizes its prominent position in debates about economic development. It has been widely observed in crosscountry analyses that standard estimates of the contribution of additional schooling to economic growth, based on productivity differences associated with differences in the level of schooling, cover only a relatively small portion of the total correlation between education and subsequent growth (Bils and Klenow 2000, Banerjee and Duflo 2004). Similarly, World Bank (2006) acknowledges that "education impact on economic growth is well-established; precisely how this happens is less well-understood." In addition to the role of education as a factor in the aggregate production function, there might be other effects of education that contribute to economic growth, such as its impact on fertility or health (Case 2006). The evidence from Ugandan villages may start teasing researchers and policy-makers with the proposition that there might be a new channel through which education promotes development - by shaping individual time discounting. 


\section{References}

Akresh, Richard and Damien de Walgue. 2008. "Armed Conflict and Schooling: Evidence from the 1994 Rwandan Genocide." IZA Discussion Paper No. 3516.

Anderson, C. Leigh, Maya Dietz, Andrew Gordon, and Marieka Klawitter. 2004."Discount rates in Vietnam." Economic Development and Cultural Change 52(4):873-887.

Anderson, Siwan and Jean-Marie Baland. 2002."The Economics of Roscas and Intrahousehold Resource Allocation." Quarterly Journal of Economics 117(3):963-995. Appleton, Simon, John Hoddinott, and John MacKinnon. 1996."Education and health in subSaharan Africa." Journal of International Development 8(3):307-339.

Armendáriz De Aghion, Beatriz and Jonathan Morduch. 2005. The Economics of Microfinance. Cambridge, MA: MIT Press.

Banerjee, Abhijit Vinayak and Esther Duflo. 2004. "Growth Theory Through the Lens of Development Economics." In Handbook of Economic Growth, ed. Phillipe Aghion and Steven N. Durlauf.: Elsevier.

Bauer, Michal and Julie Chytilová. 2008. "Do Children Make Women More Patient? Experimental Evidence from Indian Villages." Charles University, mimeo. Bauer, Michal, Julie Chytilova, and Jonathan Morduch. 2008. "Behavioral Foundations of Microcredit: Experimental and Household Survey Evidence from Rural India." NYU, mimeo. Baum, Christopher F., Mark E. Schaffer, and Steven Stillman. 2007. "Enhanced routines for instrumental variables/GMM estimation and testing." Boston College Working Paper No. 667.

Becker, Gary S. and Casey B. Mulligan. 1997."The Endogenous Determination of Time Preference." Quarterly Journal of Economics 112(3):729-758.

Bils, Mark and Peter J. Klenow. 2000."Does Schooling Cause Growth?" American Economic Review 90(5):1160-1183. 
Binswanger, Hans B. 1980."Attitudes toward Risk: Experimental Measurement in Rural India." American Journal of Agricultural Economics 62(3):395-407.

Böhm-Bawerk, Eugen V. 1971 [1891]. The Positive Theory of Capital. William Smart, trans. Freeport, NY: Books for Libraries Press.

Camerer, Colin and Robin Hogarth. 1999."The Effects of Financial Incentives in Experiments: A Review and Capital-Labor-Production Framework." Journal of Risk and Uncertainty 19(1-3):7-42.

Card, David. 1999. "The causal effect of education on earnings." In Handbook of Labor Economics, ed. Orley C. Ashenfelter and David Card.: Elsevier.

Cardenas, Juan Camilo and Jeffrey P. Carpenter. 2005. "Experiments and Economic Development: Lessons from Field Labs in the Developing World." Case, Anne. 2006. "The Primacy of Education." In Understanging Poverty, ed. Abhijit Vinayak Banerjee, Roland Benabou and Dilip Mookherjee. Oxford, UK: Oxford University Press.

Chesterfield, Ray, Kjell I. Enge and Pilar Martínez-Enge. 2001. “Girl’s Education and Crises.” Prepared for United States Agency for International Development. Coller, Maribeth and Melonie B. Williams. 1999."Eliciting Individual Discount Rates." Experimental Economics 2(2):107-127.

Collier, Paul and Ritva Reinikka, eds. 2001. Uganda's Recovery: The Role Farms, Firms, and Government. : World Bank Publications.

Doepke, Matthias and Fabrizio Zilibotti. 2006. "Patience Capital, Occupational Choice, and the Spirit of Capitalism." UCLA Working Paper 848.

Dohmen, Thomas, Armin Falk, David Huffman and Uwe Sunde. 2007. "Are Risk Aversion and Impatience Related to Cognitive Ability?" IZA Discussion Paper 2735. 
Duflo, Esther. 2006. "Poor but Rational." In Understanding Poverty, ed. Abhijit Vinayak Banerjee, Roland Benabou and Dilip Mookherjee. Oxford, UK: Oxford University Press.

Duflo, Esther. 2001."Schooling and Labor Market Consequences of School Construction in Indonesia: Evidence from an Unusual Policy Experiment." American Economic Review 91(4):795-813.

Duflo, Esther and Lucia Breierova. 2004. "The Impact of Education on Fertility and Child Mortality: Do Fathers Really Matter Less Than Mothers?" NBER Working Paper No. W10513.

Duflo, Esther, Michael Kremer, and Jonathan Robinson. 2006. "Why Don’t Farmers Use Fertilizer: Evidence from Field Experiments in Western Kenya." MIT, mimeo.

Frederick, Shane, George Loewenstein, and Ted O'Donoghue. 2002."Time Discounting and Time Preference: A Critical Review." Journal of Economic Literature 40(2):351-401. Furley, Oliver. 1988. "Education in post-independence Uganda: change amidst strife." In Uganda Now: Between Decay \& Development, ed. Holger Bernt Hansen and Michael Twaddle. London, UK: James Currey.

Hamoudi, Amar and Duncan Thomas. 2006. "Do You Care? Altruism and Inter-generational Exchanges in Mexico." UCLA.

Harrison, Glenn W., Morten Igel Lau, E. Elisabet Rutström, and Melonie B. Sullivan. 2005. "Eliciting Risk and Time Preferences Using Field Experiments: Some Methodological Issues." In

Field Experiments in Economics, ed. J. Carpenter, G. W. Harrison and J. A. List. Greenwich: CT: JAI Press.

Harrison, Glenn W., Morten Igel Lau, and Melonie B. Williams. 2002."Estimating Individual Discount Rates in Denmark: A Field Experiment." American Economic Review 92(5):16061617. 
Heyneman, Stephen P. 1983."Education during a Period of Austerity: Uganda, 1971-1981." Comparative Education Review 27(3):403-413.

Johnson, Matthe W. and Warren K. Bickel. 2002."Within-Subject Comparison of Real and Hypothetical Money Rewards in Delay Discounting." Journal of the Experimental Analysis of Behavior 77(2):129-146.

Kaduuli, Stephen. 2006. "Kwandhula - Cultural Engagement and Marriage in Busoga and Buganda." Social Science Research Network.

Kirby, K. and N. Marakovic. 1996."Delay-discounting probabilistic rewards: Rates decrease as amounts increase." Psychonomic Bulletin and Review 3(1):100-104.

Kirby, Kris N., Ricardo Godoy, Victoria Reyes-García, Elizabeth Byron, Lilian Apaza, William Leonard, et al. 2002."Correlates of delay-discount rates: Evidence from Tsimane' Amerindians of the Bolivian rain forest." Journal of Economic Psychology, 23(3):291-316. Lawrance, Emily C. 1991."Poverty and the Rate of Time Preference: Evidence from Panel Data." Journal of Political Economy 99(1):54.

Madden, Gregory J., Andrea M. Begotka, Bethany R. Raiff, and Lana L. Kastern. 2003."Delay Discounting of Real and Hypothetical Rewards." Experimental and Clinical Psychopharmacology 11(2):139-145.

McClure, Samuel M., David I. Laibson, George Loewenstein, and Jonathan D. Cohen. 2004."Separate Neural Systems Value Immediate and Delayed Monetary Rewards." Science 306(5695):503-507.

McKenzie, David J. and Christopher Woodruff. 2006."Do Entry Costs Provide an Empirical Basis for Poverty Traps? Evidence from Mexican Microenterprises." Economic Development and Cultural Change 55(1):3-42.

Metcalfe, Janet and Walter Mischel. 1999."A Hot/Cool-System Analysis of Delay of Gratification: Dynamics of Willpower." Psychological Review 106(1):3-19. 
Mischel, Walter, Yuichi Shoda, and Monica L. Rodriguez. 1989."Delay of gratification in children." Science 244(4907):933-938.

Mullainathan, Sendhil. 2005. "Development Economics Through the Lens of Psychology." In Annual Wold Bank Conference in Development Economics 2005: Lessons from Experience, ed. Francois Bourguignon and Boris Pleskovic. Oxford, UK: Oxford University Press. Pender, John L. 1996."Discount rates and credit markets: Theory and evidence from rural india." Journal of Development Economics 50(2):257-296.

Platteau, Jean-Phillipe. 2000. Institutions, Social Norms, and Economic Development. London: Routledge.

Shonkoff, Jack and Deborah Phillips, eds. 2000. From Neurons to Neighborhoods: The Science of Early Childhood Development. Washington, DC: National Academy Press. Tanaka, Tomomi, Colin F. Camerer, and Quang Nguyen. 2006. "Preferences, poverty, and politics: Field Experiments and Survey Data from Vietnam." Caltech, mimeo.

Thomas, Duncan. 1990."Intra-household Resource Allocation: An Inferential Approach." Journal of Human Resources 26(1):635-664.

Uganda Bureau of Statistics. 2002. "Ugandan Census 2002."

World Bank. 2002. "Achieving EFA in Uganda: the Big Bang approach." 
Table 1

SAMPLE DESCRIPTIVE STATISTICS (MEANS)

\begin{tabular}{|c|c|c|c|c|c|c|}
\hline & \multirow[t]{2}{*}{ Total } & \multicolumn{2}{|c|}{ Sex } & \multicolumn{3}{|c|}{ Age group } \\
\hline & & Male & Female & $15-19$ & $20-29$ & $30-74$ \\
\hline \multicolumn{7}{|l|}{ Frequency: } \\
\hline $\mathrm{N}$ & 856 & 465 & 391 & 324 & 291 & 241 \\
\hline Sample & 1.000 & 0.543 & 0.457 & 0.379 & 0.340 & 0.282 \\
\hline Rural Uganda $^{+}$ & 1.000 & 0.475 & 0.525 & 0.222 & 0.314 & 0.464 \\
\hline \multicolumn{7}{|l|}{ Education: } \\
\hline Completed PS - sample & 0.701 & 0.740 & 0.655 & 0.799 & 0.742 & 0.519 \\
\hline Completed PS - rural Uganda $^{+}$ & 0.382 & 0.426 & 0.336 & 0.440 & 0.459 & 0.301 \\
\hline Completed SS - sample & 0.074 & 0.086 & 0.059 & 0.000 & 0.134 & 0.100 \\
\hline Completed SS - rural Uganda ${ }^{+}$ & 0.064 & 0.080 & 0.048 & 0.015 & 0.097 & 0.065 \\
\hline \multicolumn{7}{|l|}{ Age: } \\
\hline Sample & 25.811 & 26.112 & 25.453 & 16.935 & 24.017 & 39.909 \\
\hline Rural Uganda $^{+}$ & 31.921 & 31.884 & 31.955 & 16.897 & 24.116 & 44.411 \\
\hline \multicolumn{7}{|l|}{ Family: } \\
\hline Married & 0.431 & 0.411 & 0.455 & 0.068 & 0.436 & 0.913 \\
\hline Strong clan linkage & 0.188 & 0.252 & 0.113 & 0.179 & 0.141 & 0.257 \\
\hline \multicolumn{7}{|l|}{ Profession: } \\
\hline Farmer & 0.409 & 0.359 & 0.468 & 0.148 & 0.447 & 0.714 \\
\hline Non-farm self-employed & 0.057 & 0.075 & 0.036 & 0.009 & 0.065 & 0.112 \\
\hline Employed & 0.131 & 0.140 & 0.120 & 0.006 & 0.241 & 0.166 \\
\hline Other & 0.403 & 0.426 & 0.376 & 0.836 & 0.247 & 0.008 \\
\hline
\end{tabular}

NOTE.- ${ }^{+}$Source: Uganda Bureau of Statistics (2002), data for population of rural Uganda in the age group 15-74. 


\section{Table 2}

AVERAGE DISCOUNT RATE (MEANS AND STANDARD DEVIATIONS)

All Male $\quad$ Female

Education:

$\begin{array}{lccc}\text { Lower PS (1-4 classes) } & 4.598 & 3.643 & 5.303 \\ \text { Higher PS (5-7 classes) } & (2.715) & (3.039) & (2.280) \\ & 4.519 & 4.551 & 4.489 \\ \text { Lower SS (8-9 classes) } & (2.634) & (2.682) & (2.601) \\ \text { Higher SS (10-13 classes) } & 3.911 & 4.106 & 3.625 \\ & (2.914) & (2.837) & (3.020) \\ \text { Completed SS and higher education } & 3.447 & 3.398 & 3.508 \\ & (2.907) & (2.870) & (2.960) \\ & 3.218 & 2.850 & 3.859 \\ & (2.787) & (2.828) & (2.652)\end{array}$

Age:

Young $(<19)$

$\begin{array}{lll}3.368 & 3.679 & 3.016\end{array}$

(2.915) (2.902) (2.899)

Middle-aged (20-29)

$3.989 \quad 3.701 \quad 4.312$

Old (>29)

(2.805) (2.810) (2.773)

$4.339 \quad 4.020 \quad 4.775$

(2.757) (2.876) (2.536)

Clan linkage:

Weak

$\begin{array}{lll}3.718 & 3.614 & 3.823\end{array}$

(2.899) (2.899) (2.900)

Strong

$4.433 \quad 4.308 \quad 4.767$

(2.607) (2.694) (2.357)

Proffesion:

\begin{tabular}{lccc} 
Farmer & 4.358 & 4.219 & 4.485 \\
Non-farm self-employed & $(2.719)$ & $(2.794)$ & $(2.650)$ \\
& 4.020 & 3.907 & 4.304 \\
Employed & $(2.655)$ & $(2.651)$ & $(2.742)$ \\
& 3.897 & 3.419 & 4.559 \\
Other & $(2.875)$ & $(2.964)$ & $(2.637)$ \\
& 3.301 & 3.525 & 3.000 \\
& $(2.932)$ & $(2.894)$ & $(2.966)$ \\
\hline
\end{tabular}


Table 3

CORRELATES OF DISCOUNT RATE: OLS

\begin{tabular}{|c|c|c|c|c|c|c|c|c|c|}
\hline \multirow[t]{2}{*}{ Dependent variable } & \multicolumn{9}{|c|}{ Discount rate (\%) } \\
\hline & (1) & (2) & (3) & (4) & (5) & (6) & (7) & (8) & (9) \\
\hline & all & male & female & all & male & female & all & male & female \\
\hline \multirow[t]{2}{*}{ Education (years) } & -0.171 & -0.160 & -0.172 & -0.170 & -0.168 & -0.171 & -0.156 & -0.115 & -0.182 \\
\hline & $(0.045)^{* * *}$ & $(0.061)^{* *}$ & $(0.032)^{* * *}$ & $(0.048)^{* * *}$ & $(0.066)^{* *}$ & $(0.035)^{* * *}$ & $(0.045)^{* * *}$ & $(0.065)^{*}$ & $(0.067)^{* * *}$ \\
\hline \multirow[t]{2}{*}{ Farmer } & & & & 0.259 & -0.318 & 0.705 & 0.433 & -0.074 & 0.770 \\
\hline & & & & $(0.373)$ & $(0.596)$ & $(0.260)^{* *}$ & $(0.349)$ & $(0.493)$ & $(0.530)$ \\
\hline \multirow[t]{2}{*}{ Non-farm self-employed } & & & & -0.051 & -0.540 & 0.345 & -0.126 & -0.585 & 0.276 \\
\hline & & & & $(0.545)$ & $(0.738)$ & $(0.763)$ & $(0.518)$ & $(0.644)$ & $(0.949)$ \\
\hline \multirow[t]{2}{*}{ Employed } & & & & 0.507 & -0.203 & 1.276 & 0.494 & -0.306 & 1.300 \\
\hline & & & & $(0.389)$ & $(0.460)$ & $(0.539)^{* *}$ & $(0.414)$ & $(0.581)$ & $(0.622)^{* *}$ \\
\hline \multirow[t]{2}{*}{ Married } & & & & -0.217 & -0.090 & -0.451 & -0.253 & -0.241 & -0.391 \\
\hline & & & & $(0.244)$ & $(0.309)$ & $(0.334)$ & $(0.296)$ & $(0.449)$ & $(0.416)$ \\
\hline \multirow[t]{2}{*}{ Clan linkage } & & & & 0.470 & 0.465 & 0.580 & 0.364 & 0.409 & 0.526 \\
\hline & & & & $(0.275)$ & $(0.351)$ & $(0.465)$ & $(0.254)$ & $(0.322)$ & $(0.468)$ \\
\hline \multirow[t]{2}{*}{ Constant } & 5.451 & 2.459 & 8.397 & 5.405 & 2.913 & 8.129 & 4.659 & 2.483 & 7.571 \\
\hline & $(2.051)^{* *}$ & $(0.368)^{* * *}$ & $(0.352)^{* * *}$ & $(2.107)^{* *}$ & $(0.911)^{* *}$ & $(0.426)^{* * *}$ & $(2.089)^{* *}$ & (2.968) & $(3.030)^{* *}$ \\
\hline Cohort effects & yes & yes & yes & yes & yes & yes & yes & yes & yes \\
\hline Village fixed effects & no & no & no & no & no & no & yes & yes & yes \\
\hline Observations & 856 & 465 & 391 & 856 & 465 & 391 & 856 & 465 & 391 \\
\hline R-squared & 0.06 & 0.06 & 0.10 & 0.06 & 0.06 & 0.11 & 0.10 & 0.12 & 0.13 \\
\hline
\end{tabular}




\section{Table 4}

AVERAGE NUMBER OF SCHOOLS PER THOUSAND PEOPLE IN THE PERIOD 19412005 (MEANS AND STANDARD DEVIATIONS)

\begin{tabular}{lcc} 
& Primary Schools & Secondary Schools \\
\hline Buikwe & 0.814 & 0.017 \\
& $(0.274)$ & $(0.041)$ \\
Busagazi & 0.675 & 0.013 \\
& $(0.451)$ & $(0.047)$ \\
Bweyogerere & 0.938 & 0.102 \\
& $(0.329)$ & $(0.197)$ \\
Kasolo & 0.675 & 0.067 \\
& $(0.255)$ & $(0.101)$ \\
Kateete & 0.898 & 0.016 \\
& $(0.293)$ & $(0.030)$ \\
Kigaya & 0.592 & 0.030 \\
& $(0.296)$ & $(0.073)$ \\
Kikube & 0.694 & 0.005 \\
& $(0.211)$ & $(0.018)$ \\
Kirugu & 0.529 & 0.031 \\
& $(0.383)$ & $(0.061)$ \\
Nakifuma & 0.978 & 0.012 \\
& $(0.370)$ & $(0.030)$ \\
Lugasa & 1.107 & 0.144 \\
& $(0.365)$ & $(0.131)$ \\
\hline
\end{tabular}


Table 5

EDUCATION AND DISCOUNT RATE ACROSS SECONDARY SCHOOLS, PRIMARY SCHOOLS AND LIVING DURING CONFLICT ERA (MEANS AND STANDARD DEVIATIONS)

\begin{tabular}{|c|c|c|c|c|c|c|c|c|c|}
\hline & \multicolumn{3}{|c|}{ SS accessibility } & \multicolumn{3}{|c|}{ PS accessibility } & \multicolumn{3}{|c|}{ At PS age during conflict } \\
\hline & lower & higher & difference & lower & higher & difference & yes & no & difference \\
\hline \multicolumn{10}{|l|}{ All } \\
\hline Education & $\begin{array}{c}8.998 \\
(3.093)\end{array}$ & $\begin{array}{c}10.031 \\
(2.652)\end{array}$ & $1.033^{* *}$ & $\begin{array}{c}9.421 \\
(2.746)\end{array}$ & $\begin{array}{c}9.599 \\
(3.112)\end{array}$ & 0.178 & $\begin{array}{c}8.717 \\
(3.127)\end{array}$ & $\begin{array}{c}9.645 \\
(2.873)\end{array}$ & $0.928^{* *}$ \\
\hline Discount rate & $\begin{array}{c}4.153 \\
(2.813)\end{array}$ & $\begin{array}{c}3.543 \\
(2.876)\end{array}$ & $-0.610 * *$ & $\begin{array}{c}3.732 \\
(2.835)\end{array}$ & $\begin{array}{c}3.981 \\
(2.882)\end{array}$ & 0.249 & $\begin{array}{c}4.520 \\
(2.730)\end{array}$ & $\begin{array}{c}3.736 \\
(2.867)\end{array}$ & $-0.784 * *$ \\
\hline \multicolumn{10}{|l|}{ Men } \\
\hline Education & $\begin{array}{c}9.276 \\
(3.276)\end{array}$ & $\begin{array}{l}10.356 \\
(2.381)\end{array}$ & $1.080^{* *}$ & $\begin{array}{c}9.586 \\
(2.830)\end{array}$ & $\begin{array}{c}9.996 \\
(3.037)\end{array}$ & 0.410 & $\begin{array}{c}9.175 \\
(3.306)\end{array}$ & $\begin{array}{c}9.912 \\
(2.842)\end{array}$ & $0.737 * *$ \\
\hline Discount rate & $\begin{array}{c}4.118 \\
(2.813)\end{array}$ & $\begin{array}{c}3.418 \\
(2.877)\end{array}$ & $-0.700 * *$ & $\begin{array}{c}3.840 \\
(2.812)\end{array}$ & $\begin{array}{c}3.733 \\
(2.929)\end{array}$ & -0.107 & $\begin{array}{c}4.341 \\
(2.855)\end{array}$ & $\begin{array}{c}3.673 \\
(2.854)\end{array}$ & -0.668 \\
\hline \multicolumn{10}{|l|}{ Women } \\
\hline Education & $\begin{array}{c}8.703 \\
(2.719)\end{array}$ & $\begin{array}{c}9.799 \\
(2.991)\end{array}$ & $1.096 * *$ & $\begin{array}{c}9.227 \\
(2.638)\end{array}$ & $\begin{array}{c}9.122 \\
(3.142)\end{array}$ & -0.105 & $\begin{array}{c}7.936 \\
(2.649)\end{array}$ & $\begin{array}{c}9.346 \\
(2.881)\end{array}$ & $1.410^{* *}$ \\
\hline Discount rate & $\begin{array}{c}4.005 \\
(2.874)\end{array}$ & $\begin{array}{c}3.930 \\
(2.840) \\
\end{array}$ & -0.075 & $\begin{array}{c}3.606 \\
(2.875) \\
\end{array}$ & $\begin{array}{c}4.278 \\
(2.803) \\
\end{array}$ & $0.672^{* *}$ & $\begin{array}{c}4.824 \\
(2.503) \\
\end{array}$ & $\begin{array}{c}3.807 \\
(2.884) \\
\end{array}$ & $-1.017^{* *}$ \\
\hline
\end{tabular}

NOTE. - ** significant at 5\% (t-test). Higher and lower level of accessility is divided according to the median value of the measures. 


\section{Table 6}

\section{THE EFFECT OF EDUCATION ON DISCOUNT RATE: 2SLS (INSTRUMENTAL VARIABLES: ACCESS TO PRIMARY AND}

SECONDARY SCHOOLS)

\begin{tabular}{|c|c|c|c|c|c|c|c|c|c|c|c|c|}
\hline \multirow[b]{2}{*}{ Cohort effects } & \multicolumn{4}{|c|}{ IV: Number of secondary schools } & \multicolumn{4}{|c|}{ IV: Number of primary schools } & \multicolumn{4}{|c|}{ IV: Number of primary and secondary schools } \\
\hline & yes & yes & yes & yes & yes & yes & yes & yes & yes & yes & yes & yes \\
\hline Observable characteristics & no & no & yes & yes & no & no & yes & yes & no & no & yes & yes \\
\hline \multirow[t]{4}{*}{ Village fixed effects } & no & no & no & no & no & no & no & no & no & no & no & no \\
\hline & \multicolumn{12}{|c|}{ 2SLS: Discount rate (\%) } \\
\hline & $(1)$ & $(2)$ & (3) & (4) & $(5)$ & (6) & (7) & $(8)$ & $(9)$ & $(10)$ & $(11)$ & $(12)$ \\
\hline & male & female & male & female & male & female & male & female & male & female & male & female \\
\hline \multirow[t]{3}{*}{ Education (years) } & -0.600 & -0.085 & -0.948 & -0.115 & -0.702 & 17.132 & -0.960 & 19.149 & -0.591 & -0.313 & -0.948 & -0.315 \\
\hline & $(0.234)^{* *}$ & $(0.166)$ & $(0.320)^{* * *}$ & $(0.162)$ & $(0.525)$ & (599.749) & $(0.630)$ & (671.537) & $(0.232)^{* *}$ & $(0.180)^{*}$ & $(0.320)^{* * *}$ & $(0.169) *$ \\
\hline & \multicolumn{12}{|c|}{ First stage: Education (years) } \\
\hline Number of SS & 4.949 & 2.684 & 3.125 & 3.096 & & & & & 5.611 & 4.335 & 3.398 & 5.022 \\
\hline & $(0.728)^{* * *}$ & $(1.265)^{*}$ & $(0.759)^{* * *}$ & $(1.101)^{* *}$ & & & & & $(1.032)^{* * *}$ & $(1.969)^{*}$ & $(1.123)^{* *}$ & $(1.536)^{* * *}$ \\
\hline \multirow[t]{2}{*}{ Number of PS } & & & & & 1.096 & 0.036 & 0.775 & 0.032 & -0.679 & -1.660 & -0.274 & -1.913 \\
\hline & & & & & $(1.108)$ & $(1.344)$ & $(0.683)$ & $(1.212)$ & $(0.594)$ & $(1.064)$ & $(0.526)$ & $(0.683)^{* *}$ \\
\hline Underidentification test (p-value) & 0.070 & 0.227 & 0.069 & 0.150 & 0.422 & 0.977 & 0.372 & 0.977 & 0.021 & 0.213 & 0.093 & 0.081 \\
\hline Weak identification test (F stat.) & 46.273 & 4.504 & 16.933 & 7.905 & 0.978 & 0.001 & 1.288 & 0.001 & 18.405 & 2.562 & 9.348 & 6.399 \\
\hline
\end{tabular}

NOTE. - Standard errors corrected for clustering at village level. The lower panel reports results from the first stage regression where the dependent variable is the years of schooling. The upper panel shows the results for the second stage where the dependent variable is the discount rate. In columns 1-4 the instrumental variable is the number of secondary schools per thousand of inhabitants in the particular village area when an individual was at the age of 15 years. In columns 5-8 the instrumental variable is the number primary schools per thousand of inhabitants in the particular village area when an individual was at the age of 7 years. In colums 9 -12 both the number of primary and secondary schools are used as instrumental variables. In all columns we control for cohort effects by including a dummy variable for each 5-year cohort (it equals to one if an individual was 7 years old in that particular period) starting from 1941-45. In columns 3-4,7-8 and 11-12 we control for observable characteristics (dummies for being farmer, non-farm self-employed, employed, married and having strong clan linkage).

Underidentification test statistic is Kleibergen-Paap rk LM statistic. The null hypothesis is that the equation is under-identified, i.e. that the excluded instruments are uncorrelated with the endogenous regressor. Weak identification test statistic is Kleibergen-Paap rk Wald F statistic. The null hypothesis is that excluded instruments are correlated with the endogeous regressor, but only weakly. A commonly used critical value for this test is approximately 10 (Baum et al. 2007).

* Significant at $10 \%$.

** Significant at 5\%

*** Significant at $1 \%$. 


\section{Table 7}

THE EFFECT OF EDUCATION ON DISCOUNT RATE: 2SLS (INSTRUMENTAL VARIABLE: NUMBER OF YEARS DURING AMIN'S ERA 1971-79)

\begin{tabular}{|c|c|c|c|c|c|c|c|c|}
\hline \multirow[b]{2}{*}{ Cohort effects } & \multicolumn{8}{|c|}{ IV: Number of school-age years during Amin era (1971-1979) } \\
\hline & yes & yes & yes & yes & yes & yes & yes & yes \\
\hline Observable characteristics & no & no & yes & yes & no & no & yes & yes \\
\hline \multirow[t]{4}{*}{ Village fixed effects } & no & no & no & no & yes & yes & yes & yes \\
\hline & \multicolumn{8}{|c|}{ 2SLS: Discount rate (\%) } \\
\hline & $(1)$ & $(2)$ & (3) & (4) & (5) & (6) & $(7)$ & $(8)$ \\
\hline & male & female & male & female & male & female & male & female \\
\hline \multirow[t]{3}{*}{ Education (years) } & -0.636 & -0.108 & -1.020 & -0.240 & -0.575 & 0.043 & -0.987 & 0.046 \\
\hline & $(0.288)^{* *}$ & $(0.674)$ & $(0.443)^{* *}$ & $(1.056)$ & $(0.296)^{*}$ & $(0.686)$ & $(0.596)^{*}$ & $(1.215)$ \\
\hline & \multicolumn{8}{|c|}{ First stage: Education (years) } \\
\hline \multirow[t]{2}{*}{ At PS age during war (years) } & -0.301 & -0.120 & -0.171 & -0.073 & -0.285 & -0.122 & -0.159 & -0.068 \\
\hline & $(0.111)^{* *}$ & $(0.113)$ & $(0.056)^{* *}$ & $(0.103)$ & $(0.077)^{* * *}$ & $(0.080)$ & $(0.060) * * *$ & $(0.067)$ \\
\hline Underidentification (p-value) & 0.053 & 0.281 & 0.026 & 0.453 & 0.000 & 0.119 & 0.007 & 0.294 \\
\hline Weak identification (F stat.) & 7.365 & 1.127 & 9.311 & 0.500 & 13.604 & 2.339 & 7.034 & 1.040 \\
\hline
\end{tabular}

NOTE. - In columns 1-4 the standard errors are corrected for clustering at village level, in columns 5-8 we control for village fixed effects. The lower panel reports results from the first stage regression where the dependent variable is the years of schooling. The upper panel shows the results for the second stage where the dependent variable is the discount rate. In all regressions the instrumental variable for education is the number of school-age years that overlap with the the era of Idi Amin (1971-1979). In all columns we control for cohort effects; for periods 1941-1955 and 1986-2000 we including dummies for each 5-year cohort starting from 1941-1945 and from 1986-1990, respectively; for the period 1956-1986 there is only one cohort dummy. In columns 3-4,7-8 and 11-12 we control for observable characteristics (dummies for being farmer, non-farm self-employed, employed, married and having strong clan linkage)

Underidentification test statistic is Kleibergen-Paap rk LM statistic. The null hypothesis is that the equation is under-identified, i.e. that the excluded instruments are uncorrelated with the endogenous regressor. Weak identification test statistic is Kleibergen-Paap rk Wald F statistic. The null hypothesis is that excluded instruments are correlated with the endogeous regressor, but only weakly. A commonly used critical value for this test is approximately 10 (Baum et al. 2007).

* Significant at $10 \%$.

** Significant at 5\%.

*** Significant at $1 \%$. 


\section{Table 8}

THE EFFECT OF EDUCATION ON DISCOUNT RATE: 2SLS (INSTRUMENTAL VARIABLES: ACCESS TO SECONDARY SCHOOLS AND NUMBER OF YEARS DURING AMIN'S ERA 1971-79)

\begin{tabular}{lcccc}
\hline & \multicolumn{4}{c}{ IV: Access to secondary schools and number of } \\
& school-age years during Amin era (1971-1979) \\
\hline Cohort effects & yes & yes & yes & yes \\
Observable characteristics & no & no & yes & yes \\
Village fixed effects & no & no & no & no \\
\cline { 2 - 5 } & \multicolumn{4}{c}{2 SLS: Discount rate (\%) } \\
& $(1)$ & $(2)$ & $(3)$ & $(4)$ \\
& male & female & male & female \\
Education (years) & -0.600 & -0.104 & -0.962 & -0.136 \\
& $(0.205)^{* * *}$ & $(0.246)$ & $(0.276)^{* * *}$ & $(0.214)$ \\
\cline { 2 - 5 } & & First stage: Education (years) & \\
Number of SS & 5.095 & 2.862 & 3.129 & 3.249 \\
At PS age during war (years) & $(0.696)^{* * *}$ & $(1.726)$ & $(0.732)^{* * *}$ & $(1.403)^{* *}$ \\
& -0.272 & -0.099 & -0.156 & -0.050 \\
Underidentification (p-value) & $(0.109)^{* *}$ & $(0.101)$ & $(0.054)^{* *}$ & $(0.086)$ \\
\cline { 2 - 5 } Weak identification (F stat.) & 0.097 & 0.506 & 0.046 & 0.386 \\
\hline
\end{tabular}

NOTE. - In all columns the standard errors are corrected for clustering at village level. The lower panel reports results from the first stage regression where the dependent variable is the years of schooling. The upper panel shows the results for the second stage where the dependent variable is the discount rate. In all regressions the instrumental variables for education are (1) the number of secondary schools per thousand of inhabitants in the particular village area when an individual was at the age of 15 years and (2) the number of school-age years that overlap with the the era of Idi Amin (1971-1979). In all columns we control for cohort effects; for periods 1941-1955 and 1986-2000 we include dummies for each 5-year cohort starting from 1941-1945 and from 1986-1990, respectively; for the period 1956-1986 there is only one cohort dummy. In columns 34 we control for observable characteristics (dummies for being farmer, non-farm self-employed, employed, married and having strong clan linkage).

Underidentification test statistic is Kleibergen-Paap rk LM statistic. The null hypothesis is that the equation is under-identified, i.e. that the excluded instruments are uncorrelated with the endogenous regressor. Weak identification test statistic is Kleibergen-Paap rk Wald F statistic. The null hypothesis is that excluded instruments are correlated with the endogeous regressor, but only weakly. A commonly used critical value for this test is approximately 10 (Baum et al. 2007).

* Significant at $10 \%$

** Significant at $5 \%$.

*** Significant at $1 \%$. 


\section{Table A1}

CORRELATES OF DISCOUNT RATE: ORDERED PROBIT

\begin{tabular}{|c|c|c|c|c|c|c|c|c|c|}
\hline \multirow[t]{2}{*}{ Dependent variable } & \multicolumn{9}{|c|}{ Discount rate } \\
\hline & (1) & $(2)$ & (3) & (4) & (5) & (6) & (7) & (8) & (9) \\
\hline & all & male & female & all & male & female & all & male & female \\
\hline \multirow[t]{2}{*}{ Education (years) } & -0.067 & -0.051 & -0.083 & -0.066 & -0.052 & -0.086 & -0.061 & -0.033 & -0.088 \\
\hline & $(0.018)^{* * *}$ & $(0.027)^{*}$ & $(0.015)^{* * *}$ & $(0.022)^{* * *}$ & $(0.030)^{*}$ & $(0.017)^{* * *}$ & $(0.019)^{* * *}$ & $(0.027)$ & $(0.029)^{* * *}$ \\
\hline Cohort effects & yes & yes & yes & yes & yes & yes & yes & yes & yes \\
\hline Observable characteristics & no & no & no & yes & yes & yes & yes & yes & yes \\
\hline Village fixed effects & no & no & no & no & no & no & yes & yes & no \\
\hline Observations & 856 & 465 & 391 & 856 & 465 & 391 & 856 & 465 & 391 \\
\hline
\end{tabular}

465

391

856

clustering at the village level. In columns 7-9, village fixed effects are included. In all columns we control for cohort effects by including a dummy variable for each 5-year cohort (it equals to one if an individual was 7 years old in that particular period) starting from 1941-45.In columns 4-9 we control for observable characteristics (dummies for being farmer, non-farm self-employed, employed, married and having strong clan linkage).

* Significant at $10 \%$.

** Significant at 5\%.

*** Significant at $1 \%$. 
Figure 1

AVERAGE EDUCATION OF MEN AND YEAR OF BIRTH

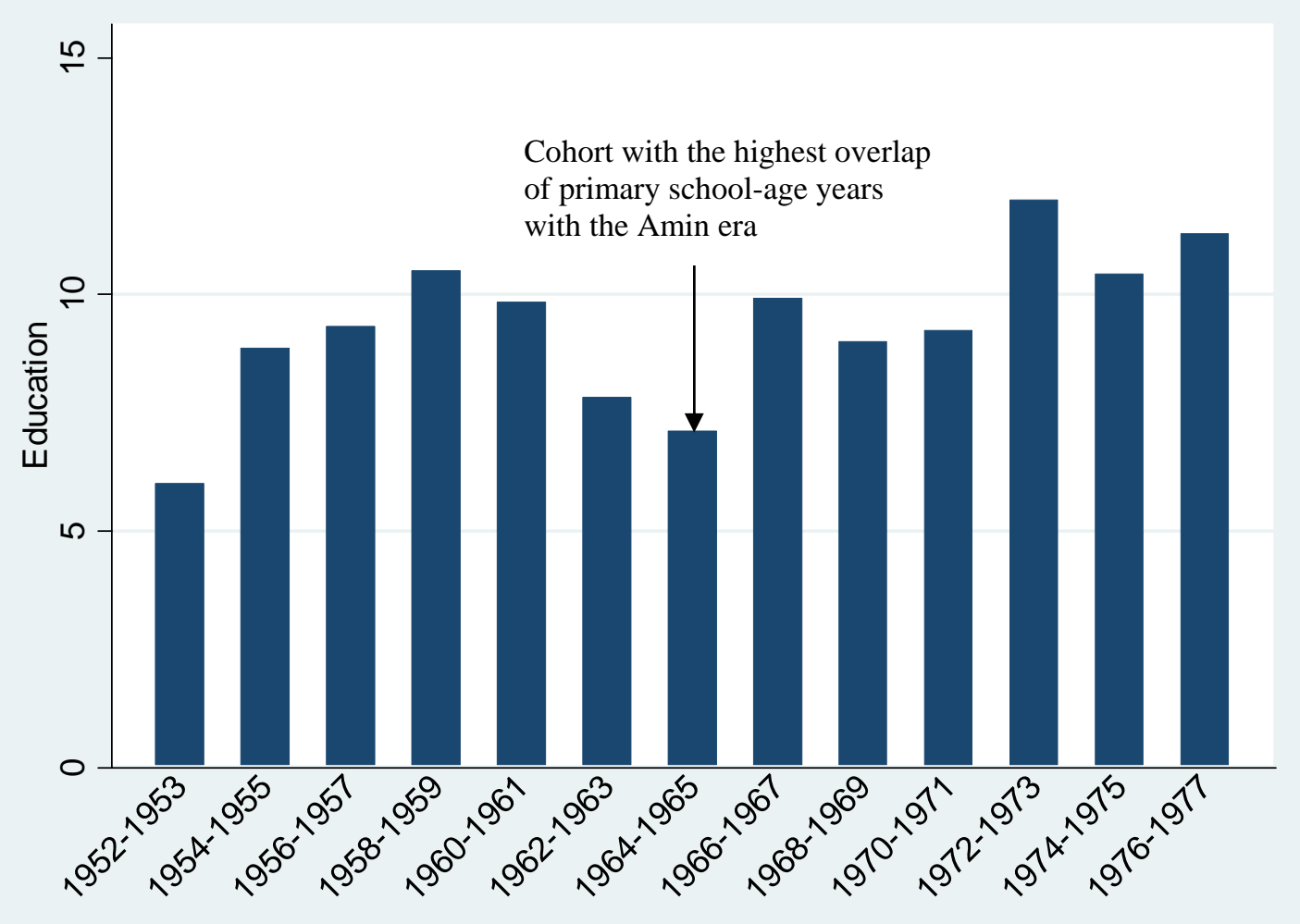

